\title{
PERENCANAAN SISTEM INSTALASI PENGOLAHAN AIR LIMBAH KOMUNAL DI PERUMAHAN GRAND VILLE TABA LESTARI, KOTA LUBUKLINGGAU, PROVINSI SUMATERA SELATAN
}

\author{
Okma Yendri ${ }^{1)}$, Herpi Deska Ardinata ${ }^{2)}$ \\ ${ }^{1,2)}$ Program Studi Teknik Sipil, Fakultas Teknik, Universitas Musi Rawas \\ Jl. Pembangunan Komplek Perkantoran Pemda Musi Rawas, Lubuklinggau
}

\begin{abstract}
The purpose of this research are to plan, design and estimate the construction cost of a communal wastewater treatment system in the Grand Ville Taba Lestari housing town of Lubuklinggau. The domestic wastewater, comes from businesses, residential activities, restaurants, offices, apartments and dormitories. The wastewater distribution system for residential area uses a shallow sewer system, namely domestic wastewater from sanitary ware (latrines, sinks, floor drain, kitchen sink, etc.) directly connected using a wastewater pipe and the wastewater distribution system in this design, uses a gravity system. Communal wastewater treatment plant is expected to prevent and reduce the occurrence of environmental pollution. From the site-plan, the maximum number of occupant are 369 persons, resulting in a wastewater debit of $40.51 \mathrm{~m}^{3} /$ day. The designed dimensions of the wastewater treatment plant are based on the amount of wastewater produced, which is $9.5 \mathrm{~m}$ long, $3 \mathrm{~m}$ wide with a depth of $2 \mathrm{~m}$. Piping network are $475.50 \mathrm{~m}$ of parcel pipe, $478.93 \mathrm{~m}$ of service pipe, $434.6 \mathrm{~m}$ of lateral pipe and $3 \mathrm{~m}$ of main pipe. The cost required for constructing the communal wastewater treatment plant in the Grand Ville Taba Lestari Housing is Rp. 335,500,000.00.-.
\end{abstract}

Key Words: communal wastewater treatment plant, domestic wastewater, wastewater discharge

\section{PENDAHULUAN}

Kota Lubuklinggau adalah kota setingkat kabupaten paling barat wilayah provinsi Sumatera Selatan, berbatasan langsung dengan kabupaten Rejang Lebong, Provinsi Bengkulu. Kota ini merupakan pemekaran dari kabupaten Musi Rawas yang memiliki delapan kecamatan selaku penunjang pemerintahan kota.

Tingkat pencemaran berbanding lurus dengan angka pertumbuhan penduduk di suatu wilayah. Semakin padat penduduk di suatu wilayah, maka potensi lingkungan tersebut rusak akan semakin besar. Penambahan ini menyebabkan meningkatnya kuantitas dan kualitas air limbah yang dihasilkan, sehingga diperlukan adanya instalasi pengelolaan air limbah yang lebih baik karena pengelolaan yang ada belum optimal (Wulandari, 2014).

Meningkatnya pembangunan di kota-kota sedang memberikan dampak pada pertumbuhan penduduk. Peningkatan jumlah penduduk berbanding lurus dengan pertumbuhan di berbagai sektor penunjang kehidupan lainnya seperti sektor pemukiman dan perumahan. Pertumbuhan sektor perumahan dan pemukiman tersebut menuntut adanya pembangunan infrastruktur dasar pelayanan publik yang lebih baik. Kurangnya pelayanan prasarana lingkungan seperti infrastruktur air bersih dan sistem sanitasi, penyediaan rumah, dan transportasi yang baik untuk memenuhi kebutuhan pertumbuhan kota, dapat menjadi penyebab timbulnya berbagai masalah di kota-kota pada negara berkembang.

Hampir seluruh aktivitas yang dilakukan menghasilkan limbah, mulai dari proses metabolisme di dalam tubuh hingga proses industri yang berbasis teknologi tinggi. Menurut UU No.23 Tahun 1997 (Kemen LH, 1997) tentang pengelolaan lingkungan hidup, pengertian limbah adalah sisa suatu usaha dan/atau kegiatan. Sugiharto (1987) mengklasifikasikan sumber air limbah menjadi dua bagian, yaitu air limbah rumah tangga dan air limbah industri. Sumber utama air limbah domestik (rumah tangga) dari masyarakat berasal dari area perumahan, perdagangan, kelembagaan dan rekreasi. Sedangkan limbah non domestik berasal dari industri, pertanian, peternakan, perikanan, transportasi dan sumber - sumber lain. Indikator yang umum diketahui pada pemeriksaan pencemaran air adalah $\mathrm{pH}$ atau konsentrasi ion hidrogen, oksigen terlarut (Dissolved Oxygen, DO), kebutuhan oksigen biokimia (Biochemiycal Oxygen Demand, BOD) serta kebutuhan oksigen kimiawi (Chemical Oxygen Demand, COD).

Berdasarkan kebutuhan infrastruktur pengelolaan limbah cair domestik pada salah satu area pemukiman di kota Lubuk Linggau, dilakukan penelitian yang bertujuan untuk: 
a. Merencanakan sistem instalasi pengolahan air limbah komunal di perumahan Grand Ville Taba Lestari, kota Lubuklinggau dan;

b. Menghitung kebutuhan biaya untuk pembangunan sistem instalasi pengolahan air limbah komunal di perumahan Grand Ville Taba Lestari, kota Lubuklinggau.

\section{METODOLOGI}

Langkah - langkah dan metode yang digunakan dalam penelitian ini terkait dengan pengolahan data yang didapat dari lokasi penelitian dan instansi terkait. Untuk memperoleh data yang bersifat teoritis dan mengandung unsur yang besifat ilmiah serta dapat dipertanggung jawabkan, maka pengumpulan dan pengolahan data dilakukan dalam beberapa tahap, yang meliputi:

- Identifikasi Masalah

Untuk dapat mengatasi permasalahan secara tepat, maka pokok permasalahan harus diketahui terlebih dahulu. Solusi masalah yang akan dibuat harus mengacu pada permasalahan yang terjadi.

- Studi Literatur

Studi literatur dilakukan untuk mendapatkan acuan dalam analisis data. Studi pustaka dilakukan dengan mengumpulkan data-data dari mempelajari buku, kumpulan jurnal atau literatur lain yang berhubungan dengan judul yang dibahas dan diperlukan sebagai referensi.

- Pengumpulan Data.

Data yang dikumpulkan meliputi :

- Data primer, yaitu: ketersediaan lahan bangunan IPAL dan jaringan perpipaan.

- Data sekunder, meliputi: site plan perumahan, jumlah rumah dan bangunan yang dilayani, denah dan tipe rumah, dan Harga Satuan Pokok Kegiatan (HSPK) Kota Lubuk Linggau.

- Pengolahan Data.

Pengolahan data meliputi: analisa debit limbah cair domestik, perhitungan dimensi bak - bak pengolah limbah, dan estimasi biaya pembangunan IPAL Komunal.

\section{HASIL DAN PEMBAHASAN}

Peta skema jaringan untuk mengidentifikasi permasalahan dan merencanakan instalasi perpipaan dan bak - bak pengolah limbah tersaji dalam Gambar 3.1.

\subsection{Jumlah Rumah dan Bangunan Dilayani}

Jumlah rumah dan bangunan ruko dapat dilihat di Tabel 1.

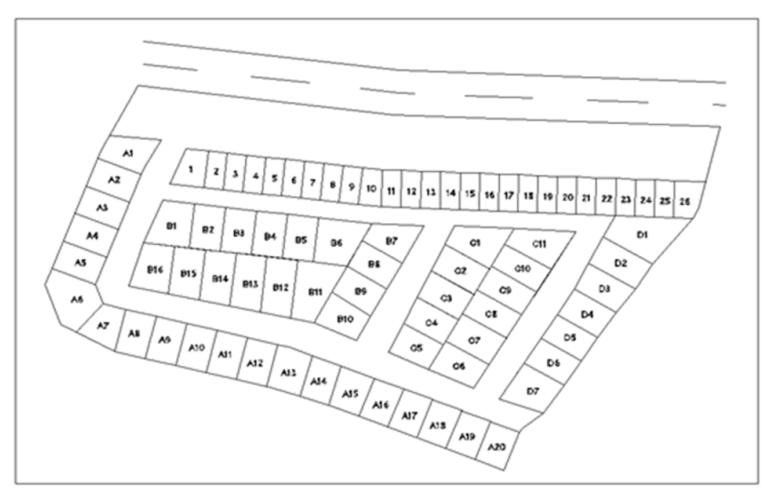

Gambar 1 Site plan perumahan

Tabel 1 Jumlah unit bangunan

\begin{tabular}{|c|c|c|c|}
\hline Blok & Unit & Alokasi & Jumlah \\
\hline A & 20 Unit & & \\
\cline { 1 - 2 } B & 16 Unit & \multirow{3}{*}{ Perumahan } & 54 \\
\hline C & 11 Unit & & \\
\hline D & 7 Unit & & 26 \\
\hline Ruko & 26 Unit & Ruko & 26 \\
\hline
\end{tabular}

\subsection{Data Umum Rumah dan Bangunan Ruko}

Bangunan di Perumahan Grand Ville Taba Lestari, antara lain:

- Data umum area bangunan ruko meliputi :

1) Panjang area bangunan : $10 \mathrm{~m}$

2) Lebar area bangunan : $5 \mathrm{~m}$

3) Luas area bangunan : $5 \mathrm{mx} 10 \mathrm{~m}=50 \mathrm{~m}^{2}$

- Data umum bangunan ruko meliputi :

1) Panjang bangunan : $8 \mathrm{~m}$.

2) Lebar bangunan : $5 \mathrm{~m}$.

3) Tinggi bangunan : $4 \mathrm{~m}$.

4) Luas bangunan : $8 \mathrm{~m} \times 5 \mathrm{~m}=40 \mathrm{~m}^{2}$.

- Data umum area rumah meliputi :

1) Panjang area rumah : $12 \mathrm{~m}$.

2) Lebar area rumah : $8 \mathrm{~m}$.

3) Luas area rumah : $12 \mathrm{~m} \times 8 \mathrm{~m}=96 \mathrm{~m}^{2}$.

- Data umum rumah meliputi :
1) Panjang rumah
$6,5 \mathrm{~m}$
2) Lebar rumah
: $6 \mathrm{~m}$.
3) Luas rumah
: $6,5 \mathrm{~m} \times 6 \mathrm{~m}=39 \mathrm{~m}^{2}$.

\subsection{Rencana Jumlah Penghuni}

Jumlah penghuni diasumsikan 1 unit rumah terdapat $1 \mathrm{KK}$ yang terdiri dari 5 orang dan 1 bangunan ruko terdapat $1 \mathrm{KK}$ yang terdiri dari 4 orang. Rencana jumlah penghuni pada keseluruhan bangunan, yaitu :

1) Berdasarkan gambaran umum, terdapat 26 unit bangunan ruko. Dengan asumsi satu unit ruko memiliki jumlah penghuni sebanyak empat orang, maka total penghuni pada bangunan ruko adalah: $26 \times 4$ orang $=104$ orang. 
2) Berdasarkan gambaran umum, terdapat 54 unit rumah. Sebagai pertimbangan, luas area satu unit rumah akan digunakan untuk bangunan IPAL. Dengan asumsi satu unit ruah dihuni lima orang, maka total penghuni pada rumah adalah: $53 \times 5$ orang $=265$ orang.

\subsection{Perhitungan Pemakaian Air Bersih}

Pemakaian air bersih pada bangunan ruko adalah 100 liter/penghuni/hari, dan rumah sebesar 120 liter/penghuni/hari. Maka, pemakaian air bersih, adalah:

- Jumlah konsumsi air bersih pada bangunan ruko:

1) Jumlah bangunan ruko : 26 unit.

2) Jumlah penghuni : 104 orang.

3) Konsumsi air bersih : 100 liter/penghuni/hari

4) Jumlah pemakaian air bersih (Q): Jumlah penghuni $\times$ pemakaian air bersih $=104 \times 100=$ 10.400 liter/hari $=10,4 \mathrm{~m}^{3} /$ hari.

Jumlah pemakaian air bersih pada rumah:

1) Jumlah rumah : 53 unit.

2) Jumlah penghuni : 265orang.

3) Konsumsi air bersih : 120 liter/penghuni/hari

4) Jumlah pemakaian air bersih (Q): Jumlah penghuni $\mathrm{x}$ konsumsi air bersih $=265 \times 120=$ 31.800 liter/hari $=31,8 \mathrm{~m}^{3} /$ hari.

Sehingga, total pemakaian air bersih $=10,4 \mathrm{~m}^{3} /$ hari $+31,8 \mathrm{~m}^{3} /$ hari $=42,2 \mathrm{~m}^{3} /$ hari.

\subsection{Perhitungan Debit Air Limbah}

Debit air limbah dihitung dengan:

1) Faktor pengembalian (x) : $80 \%$.

2) Total pemakaian air bersih : $42,2 \mathrm{~m}^{3} /$ hari.

3) Sehingga, debit air limbah $\left(\mathrm{Q}_{1}\right)$ :

$=\mathrm{x} \cdot \mathrm{Q}=80 \% \mathrm{x} 42,2 \mathrm{~m}^{3} / \mathrm{hari}=33,76 \mathrm{~m}^{3} /$ hari.

Debit air limbah saat jam puncak, adalah:

1) Koefisien saat jam sibuk : 1,2 .

2) Debit air limbah (Q1) : $33,76 \mathrm{~m}^{3} /$ hari.

3) Q1 pada saat jam puncak : koefisien saat jam sibuk $\times \mathrm{Q} 1=1,2 \times 33,76 \mathrm{~m}^{3} /$ hari $=40,51 \mathrm{~m}^{3} /$ hari.

\subsection{Perhitungan Volume Bak Penampung IPAL}

\subsubsection{Kapasitas Desain IPAL yang direncanakan}

Kapasitas yang direncanakan adalah:

1) Kapasitas pengolahan : $40,51 \mathrm{~m}^{3} /$ hari

2) BOD air limbah rata-rata : $195 \mathrm{mg} / \mathrm{l}$

3) Total efisiensi pengolahan : $90-95 \%$

\subsubsection{Bak Ekualisasi}

Bak ekualisasi merupakan bak penampung yang berfungsi untuk mengendalikan fluktuasi aliran limbah menjadi laminer atau rata sehingga tidak menganggu tahap pengolahan selanjutnya, dengan perhitungan sebagai berikut:

1) Debit air limbah : 40,51 $\mathrm{m}^{3} /$ hari $=1,69$ $\mathrm{m}^{3} / \mathrm{jam}=28,13$ liter $/$ menit

2) Retention time : 6 jam.

3) Volume bak yang diperlukan $: \frac{6}{24}$ hari $x 40,51$ $\mathrm{m}^{3} / \mathrm{hari}=10,13 \mathrm{~m}^{3}$

4) Dimensi bak :
a. Panjang : $3 \mathrm{~m}$.
b. Lebar : $3 \mathrm{~m}$.
c. Tinggi $\quad: 1,5 \mathrm{~m}$.
d. Ruang bebas : $0,5 \mathrm{~m}$.

e. Volume efektif : $3 \mathrm{~m} \times 3 \mathrm{~m} \times 1,5 \mathrm{~m}=13,5 \mathrm{~m}^{3}$.

f. Konstruksi : Beton bertulang.

g. Tebal dinding : $0,2 \mathrm{~m}$.

5) Check: Waktu tinggal (HRT) dalam bak = $\frac{3 \times 3 \times 1,5}{40,51} \times 24 \mathrm{jam}=8 \mathrm{jam}$.

\subsubsection{Bak Pengendapan Awal}

Bak dengan proses pengendapan partikel lumpur dan padatan organik, hingga total padatan tersuspensi dalam air limbah untuk dilanjutkan ke tahap selanjutnya.

1) Debit air limbah : 40,51 $\mathrm{m}^{3} /$ hari $=1,69$ $\mathrm{m}^{3} / \mathrm{jam}=28,13$ liter $/$ menit.

2) Retention time : 4 jam.

3) BOD inlet : $195 \mathrm{mg} / \mathrm{l}$.

4) Efisiensi pengolahan : $40 \%$.

5) BOD outlet : $117 \mathrm{mg} / \mathrm{l}$.

6) Volume bak yang diperlukan $=\frac{4}{24}$ hari $\mathrm{x}$ $40,51 \mathrm{~m}^{3} / \mathrm{hari}=6,75 \mathrm{~m}^{3}$

7) Dimensi bak :
a. Panjang
: $2 \mathrm{~m}$.
b. Lebar
: $3 \mathrm{~m}$
c. Tinggi
: $1,5 \mathrm{~m}$
d. Ruang bebas : $0,5 \mathrm{~m}$.
e. Volume efektif : $2 \mathrm{~m} \times 3 \mathrm{~m} \times 1,5 \mathrm{~m}=9 \mathrm{~m}^{3}$.
f. Konstruksi : Beton bertulang.
g. Tebal dinding : $0,2 \mathrm{~m}$.

8) Check:

Waktu tinggal $($ HRT $)$ dalam bak $=\frac{2 \times 3 \times 1,5}{40,51} \times 24$ jam $=5,33$ jam.

9) Beban permukaan:

(surface loading) $=\frac{40,51 \mathrm{~m} 3 / \mathrm{hari}}{2 \mathrm{~m} \times 3 \mathrm{~m}}=6,75$ $\mathrm{m}^{3} / \mathrm{m}^{2}$.hari

10) Beban permukaan saat jam puncak : $\quad 6,75$ $\mathrm{m}^{3} / \mathrm{m}^{2}$.hari $\times 2=13,50 \mathrm{~m}^{3} / \mathrm{m}^{2}$.hari.

\subsubsection{Bak Biofilter Anaerob}

Bak pengolahan air limbah secara biologi dengan media khusus yang akan menguraikan zat organik 
yang belum sempat terurai di proses pengendapan awal, dengan perhitungan sbb:

1) Debit air limbah : 40,51 $\mathrm{m}^{3} / \mathrm{hari}=1,69$ $\mathrm{m}^{3} / \mathrm{jam}=28,13$ liter $/$ menit.

2) BOD inlet : $: 117 \mathrm{mg} / \mathrm{l}$.

3) Efisiensi pengolahan : $85 \%$.

4) BOD outlet : : $17,55 \mathrm{mg} / \mathrm{l}$.

Untuk pengolahan air limbah dengan proses biofilter, standar beban BOD per volume media adalah $0,4-4,7 \mathrm{~kg} \mathrm{BOD} / \mathrm{m}^{3}$.hari. Ditetapkan beban BOD yang digunakan adalah $1 \mathrm{~kg}$ BOD $/ \mathrm{m}^{3}$.hari.

5) Beban BOD dalam air limbah: $40,51 \mathrm{~m}^{3} /$ hari $x$ $117 \mathrm{~g} / \mathrm{m}^{3}=4740 \mathrm{~g} / \mathrm{hari}=4,74 \mathrm{~kg} /$ hari.

6) Volume media yang diperlukan $=\frac{4,74 \mathrm{~kg} / \mathrm{hari}}{1 \mathrm{~kg} / \mathrm{m} 3 \cdot \mathrm{hari}}=$ $4,74 \mathrm{~m}^{3}$.

7) Volume media $=60 \%$ dari volume reaktor. Volume reaktor $=\frac{100}{60} \times 4,74 \mathrm{~m}^{3}=7,9 \mathrm{~m}^{3}$.

8) Dimensi bak :
a. Panjang
b. Lebar
: $2,5 \mathrm{~m}$.
c. Tinggi
: $3 \mathrm{~m}$.
d. Ruang bebas : $0,5 \mathrm{~m}$. $11,25 \mathrm{~m}^{3}$.
f. Konstruksi
g. Tebal dinding : $0,2 \mathrm{~m}$.
h. Ruang : 2 ruang.

e. Volume efektif : $2,5 \mathrm{~m} \times 3 \mathrm{~m} \times 1,5 \mathrm{~m}=$

9) Waktu tinggal (HRT) di dalam reaktor anaerob: $\frac{7,9}{40,51} \times 24$ jam $=4,68$ jam.

\subsubsection{Bak Pengendapan Akhir}

Bak yang berfungsi mengendapkan lumpur aktif yang mengandung mikroorganisme, setelah itu air olahan dapat dialirkan ke badan air, dengan perhitungan sbb:

1) Debit air limbah : $40,51 \mathrm{~m}^{3} /$ hari $=1,69 \mathrm{~m}^{3} / \mathrm{jam}=28,13$ liter $/$ menit.

2) Retention time : 4 jam.

3) BOD inlet : $17,55 \mathrm{mg} / \mathrm{l}$.

5) BOD Keluar : $\quad 17,55 \mathrm{mg} / \mathrm{l}$.

6) Volume bak yang diperlukan: $\frac{4}{24}$ hari $x 40,51$ $\mathrm{m}^{3} / \mathrm{hari}=6,75 \mathrm{~m}^{3}$.

7) Dimensi bak:
a. Panjang
: $2 \mathrm{~m}$.
b. Lebar
: $3 \mathrm{~m}$.
c. Tinggi
$1,5 \mathrm{~m}$
d. Ruang bebas : $0,5 \mathrm{~m}$.
e. Volume efektif : $2 \mathrm{~m} \times 3 \mathrm{~m} \times 1,5 \mathrm{~m}=9 \mathrm{~m}^{3}$
f. Konstruksi : Beton K300.
g. Tebal dinding : $0,2 \mathrm{~m}$.

8) Check:

Waktu tinggal (HRT) di dalam bak: $\frac{2 \times 3 \times 1,5}{40,51} \times$ 24 jam $=5,33$ jam.

9) Beban permukaan (surface loading): $=\frac{40,51 \mathrm{~m} 3 / \text { hari }}{2 \mathrm{~m} \times 3 \mathrm{~m}}=6,75 \mathrm{~m}^{3} / \mathrm{m}^{2}$.hari.

10) Beban permukaan saat jam puncak: $6,75 \mathrm{~m}^{3} / \mathrm{m}^{2}$.hari x $2=13,50 \mathrm{~m}^{3} / \mathrm{m}^{2}$.hari.

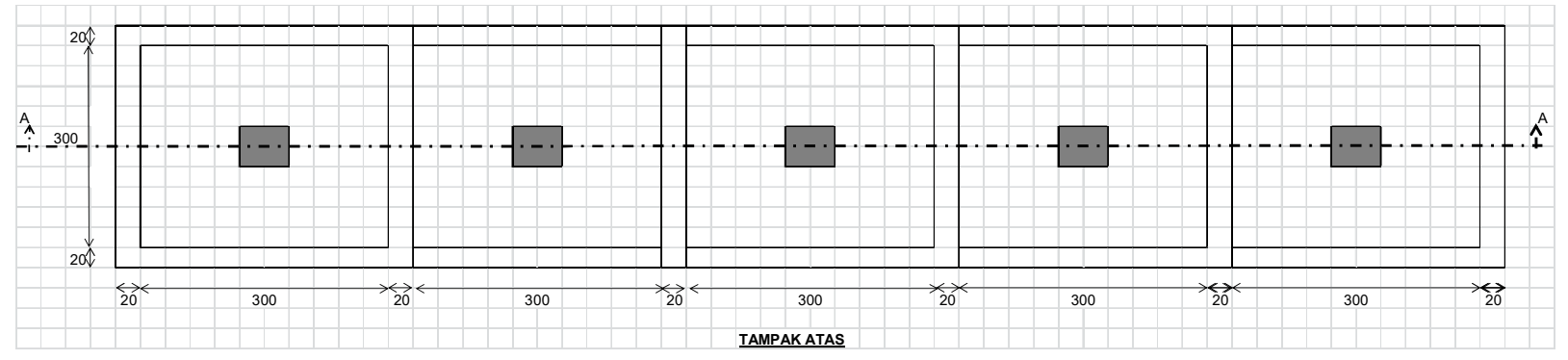

Gambar 2. Tampak atas IPAL

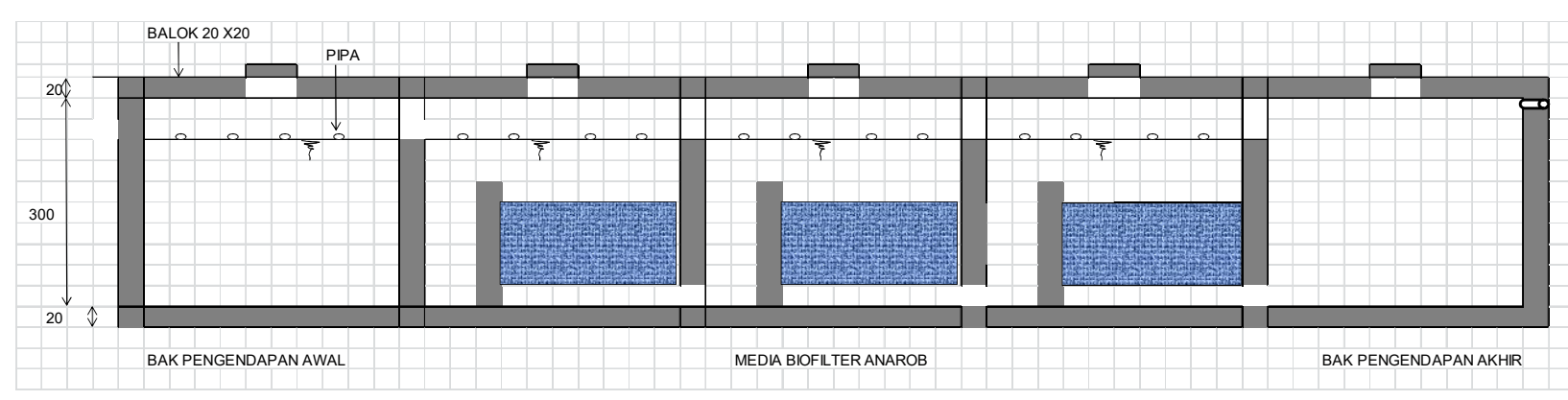

Gambar 3.Potongan memanjang IPAL 


\subsection{Bangunan Pelengkap}

Pada perencanaan IPAL Komunal ini, terdapat beberapa unit bangunan pelengkap yang dilengkapi dengan pipa masuk (inlet) dan keluar (outlet). Fungsi banguan pelengkap ini adalah untuk memudahkan dalam melakukan perawatan rutin berkala. Unit bangunan pelengkap dapat dilihat pada Tabel 2.

Bangunan pelengkap untuk setiap satu unit bangunan yang dilayani adalah satu unit bak penangkap lemak dan satu unit bak kontrol, dengan jumlah total 53 unit. Manhole melayani untuk 2 sampai 3 unit bangunan dengan jumlah total 38 unit. Lay out bangunan pelengkap dan jaringan perpipaan dapat dilihat pada Gambar 4.

Tabel 2.Unit Bangunan Pelengkap

\begin{tabular}{|c|l|c|}
\hline No. & \multicolumn{1}{|c|}{ Bangunan Pelengkap } & $\begin{array}{c}\text { Jumlah } \\
\text { Unit }\end{array}$ \\
\hline 1 & $\begin{array}{l}\text { Bak penangkap lemak (Grease } \\
\text { Trap) }\end{array}$ & 79 \\
\hline 2 & Bak kontrol & 79 \\
\hline 3 & Manhole & 38 \\
\hline
\end{tabular}

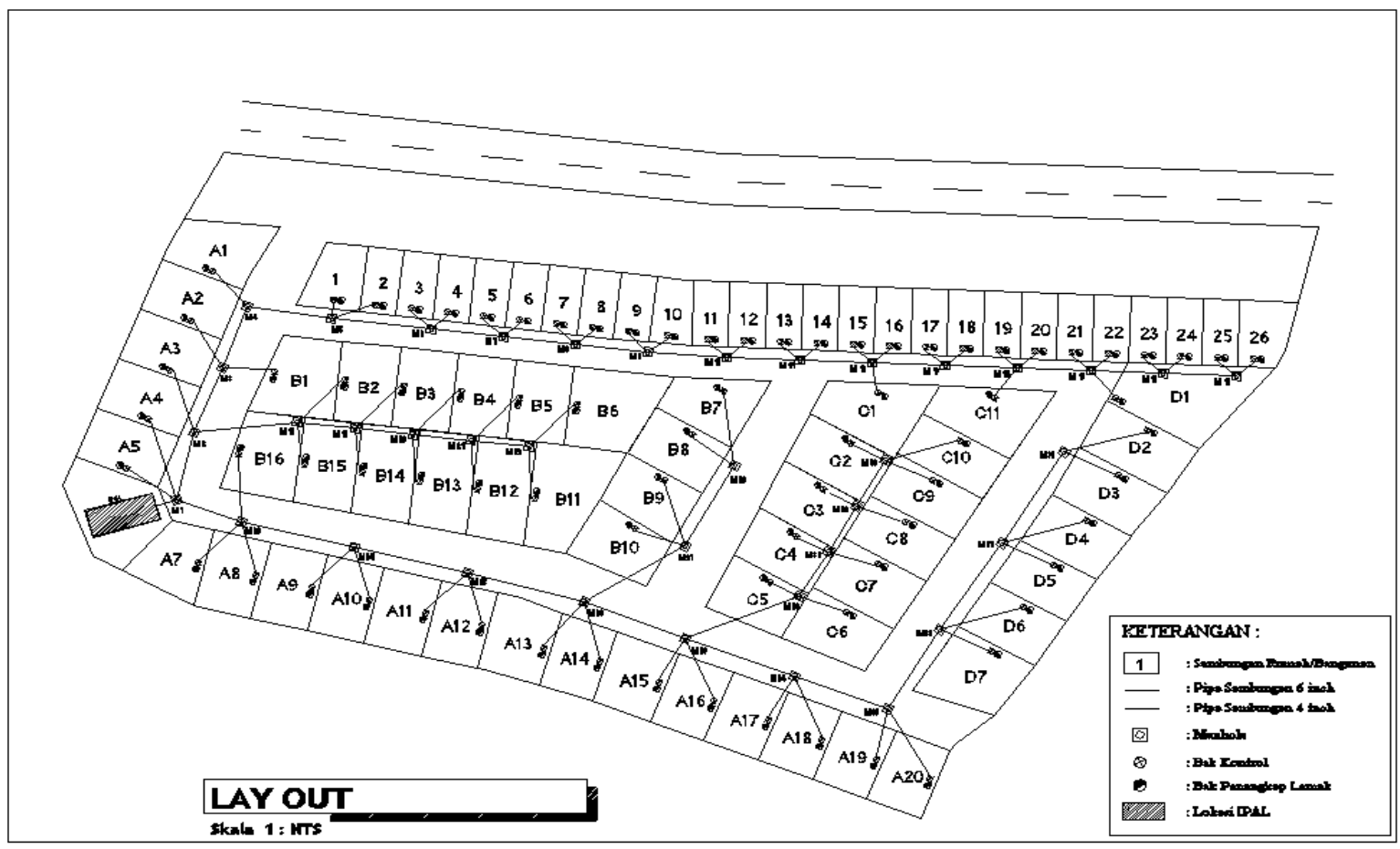

Gambar 4 Lay Out Bangunan Pelengkap dan Jaringan Perpipaan

\subsection{Jaringan Perpipaan}

Jaringan perpipaan yang direncanakan berdasarkan fungsi sistem perpipaan, yang meliputi:

\subsubsection{Pipa Persil}

Pipa persil yaitu pipa saluran yang umumnya terletak di dalam pekarangan rumah dan langsung menerima air buangan dari dapur atau kamar mandi/WC. Pipa yang dipakai adalah pipa PVC 3“. Alokasi pipa persil untuk kitchen sinks, kamar mandi dan closet tersaji dalam Tabel 3, Tabel 4 dan Tabel 5.

Tabel 3 Kebutuhan pipa persil 1 unit rumah

\begin{tabular}{|c|l|c|c|}
\hline No. & Alokasi Pipa & Ukuran & Panjang Pipa (m) \\
\hline 1 & Kitchen sinks & $3^{\prime \prime}$ & 4,5 \\
\hline 2 & Kamar mandi & $3^{\prime \prime}$ & 1,5 \\
\hline 3 & Closet & $3^{\prime \prime}$ & 1,5 \\
\hline \multicolumn{2}{|c|}{ Total } & 7,5 \\
\hline
\end{tabular}

Tabel 4 Kebutuhan pipa persil 1 unit ruko

\begin{tabular}{|c|c|c|c|}
\hline No. & Alokasi Pipa & Ukuran & Panjang Pipa (m) \\
\hline 1 & Kamar mandi & $3 "$ & 1,5 \\
\hline 2 & Closet & $3^{\prime \prime}$ & 1,5 \\
\hline \multicolumn{3}{|c|}{ Total } & 3 \\
\hline
\end{tabular}

Tabel 5 Total kebutuhan pipa persil

\begin{tabular}{|c|l|c|c|c|}
\hline No. & $\begin{array}{c}\text { Alokasi } \\
\text { Pipa }\end{array}$ & Unit & $\begin{array}{c}\text { Panjang per } \\
\text { Unit (m) }\end{array}$ & $\begin{array}{c}\text { Total } \\
\text { Panjang (m) }\end{array}$ \\
\hline 1 & Rumah & 53 & 7,5 & 397,5 \\
\hline 2 & Ruko & 26 & 3 & 78 \\
\hline \multicolumn{4}{|c|}{ Total } \\
\hline
\end{tabular}

\subsubsection{Pipa Servis}

Pipa servis yaitu pipa saluran yang menampung air buangan dari pipa-pipa persil dan terletak dijalan depan rumah. Pipa servis ini meneruskan dari bak kontrol dan bak penangkap lemak. Pipa yang dipakai adalah pipa SDR - 41 4“( Tabel 6). 
Tabel 6 Total kebutuhan pipa servis

\begin{tabular}{|c|c|c|c|}
\hline No. & Alokasi Pipa & Unit & Total Panjang (m) \\
\hline 1 & Rumah & 53 & 426,93 \\
\hline 2 & Ruko & 26 & 52 \\
\hline \multicolumn{3}{|c|}{ Total } & 478,93 \\
\hline
\end{tabular}

\subsubsection{Pipa Lateral}

Pipa lateral yaitu pipa saluran yang menerima air buangan dari pipa-pipa servis. Pipa yang dipakai adalah pipa SDR - 416 6" (Tabel 7).

Tabel 7 Total kebutuhan pipa lateral

\begin{tabular}{|c|c|c|c|}
\hline No. & Alokasi Pipa & Unit & Total Panjang (m) \\
\hline 1 & Rumah dan Ruko & 79 & 431,6 \\
\hline \multicolumn{3}{|c|}{ Total } & 431,6 \\
\hline
\end{tabular}

\subsubsection{Pipa Induk}

Pipa induk yaitu pipa saluran yang menerima air buangan dari pipa lateral dan langsung terhubung dengan instalasi pengolahan air limbah. Pipa yang dipakai adalah pipa SDR - 416 6“. Kebutuhan pipa induk sepanjang $3 \mathrm{~m}$.

\subsection{Rencana Anggaran Biaya}

Rencana anggaran biaya adalah perhitungan besarnya biaya yang diperlukan (bahan dan upah) dalam menyelesaikan suatu konstruksi bangunan. Harga satuan upah dan bahan atau material untuk dasar perhitungan biaya perencanaan didasarkan harga satuan setempat. Dalam perencanaan IPAL komunal di Perumahan Grand Ville Taba Lestari, kebutuhan biaya yang di perlukan dapat dilihat pada Tabel 8.

Tabel 8. Rekapitulasi daftar kuantitas harga pembuatan IPAL

\begin{tabular}{|c|l|c|}
\hline No & \multicolumn{1}{|c|}{ Uraian Pekerjaan } & Jumlah Harga \\
\hline 1 & Pekerjaan Persiapan & $2,374,620.00$ \\
\hline 2 & Pekerjaan IPAL BioGas & $191,915,212.75$ \\
\hline 3 & Pek. Pemasangan Pipa Ø 3” & $16,421,154.75$ \\
\hline 4 & Pek. Pemasangan Pipa Ø 4” & $22,051,134.53$ \\
\hline 5 & Pek. Pemasangan Pipa Ø 6” & $26,658,946.90$ \\
\hline 6 & Pek. Bak Kontrol \& Grease Trap & $38,342,813.90$ \\
\hline 7 & Pekerjaan Manhole & $37,723,261.33$ \\
\hline 8 & Pengadaan Pipa & 110.566 .077 .33 \\
\hline \multicolumn{2}{r}{ Total (RP) } & $335,487,144.16$ \\
\hline \multicolumn{2}{r}{ Dibulatkan (RP) } & 335.500 .000 .00 \\
\hline
\end{tabular}

\section{KESIMPULAN}

a. Pada Perumahan Grand Ville Taba Lestari, dari seluruh unit rumah dan bangunan ruko (estimasi 369 jiwa), diperkirakan menghasilkan debit air limbah domestik sebanyak $40,51 \mathrm{~m}^{3}$ setiap harinya.

b. Dimensi bak Instalasi Pengolahan Air Limbah berdasarkan jumlah debit air limbah yang dihasilkan yaitu; panjang 9,5 m, lebar $3 \mathrm{~m}$ dengan kedalaman $2 \mathrm{~m}$. Jaringan perpipaan untuk pipa persil sepanjang $475,50 \mathrm{~m}$, pipa servis $478,93 \mathrm{~m}$, pipa lateral $434,6 \mathrm{~m}$, dan pipa induk 3 $\mathrm{m}$.

c. Kebutuhan biaya yang diperlukan untuk pembuatan IPAL komunal di Perumahan Grand Ville Taba Lestari adalah Rp. 335.500.000.00.-.

\section{UCAPAN TERIMA KASIH}

Ucapan terima kasih kepada manajemen Perumahan Grand Ville Taba Lestari Kota Lubuklinggau.

\section{REFERENSI}

Darmasetiawan, I. M. (2004). Sarana Sanitasi Perkotaan. Jakarta: Ekamitra Engineering.

Kementrian Lingkungan Hidup (1997). Undang-Undang Republik Indonesia Nomor 23 Tahun 1997 tentang Pengelolaan Lingkungan Hidup. Jakarta

Kementrian Pekerjaan Umum dan Perumahan Rakyat (2018). Petunjuk Teknis Sanimas IDB. Jakarta.

Menteri Negara Lingkungan Hidup (2003). Baku Mutu Air Limbah Domestik. Jakarta

Metcalf, Eddy. (1991). Wastewater Engineering Treatment. New Delhi.

Peraturan Menteri Pekerjaan Umum No. 11 Tahun 2013. Pedoman Analisis Harga Satuan Pekerjaan.

Said, I. N. (2006). Instalasi Pengolahan Air Limbah Rumah Sakit. Jakarta.

Sugiharto. (1987). Dasar-Dasar Pengolahan Air Limbah. Jakarta: UI Press.

Wulandari P., R. (2014). Perencanaan Pengolahan Air Limbah Sistem Terpusat (Studi Kasus Di Perumahan PT.

Pertamina Unit Pelayanan III Plaju - Sumatera Selatan). 